\title{
Taking Responsibility in an Unjust World
}

\author{
Joe Hoover \\ Queen Mary University of London, UK
}

Brooke A. Ackerly, Just Responsibility: A Human Rights Theory of Global Justice, New York: Oxford University Press, 2018.

Michael Goodhart, Injustice: Political Theory for the Real World, New York: Oxford University Press, 2018

Catherine Lu, Justice and Reconciliation in World Politics, Cambridge: Cambridge University Press, 2018.

Our is an age of irresponsibility and injustice. The associations that make responsibility and justice possible have broken down due to negligence, deliberate subversion, and changed social conditions. To be responsible is to be bound by legitimate social rules and to be able to demand recognition of the social rules from others. Responsibility is the activity of calling and responding appropriately in our social transactions, while justice, most simply, is our reflective judgment of the quality of the rules and practices by which we live. Our responsibility, and our capacity to be responsible, is dependent upon the justice of the rules and practices with which we organise social life, upon the fairness of the way we bind ourselves together. Justice and responsibility, then, are associational concepts that characterise our relationships, as well as the norms and institutions through which those relationships are built. Therefore, to live in an irresponsible and unjust age means social rules and practices fail us, as our actual experience is not adequately reflected in the institutional and normative world we inherit. We no longer know how to respond to each other.

Convention in political theory dictates we work out an ideal conception of justice, which provides a guide for the non-ideal world of lived experience. Yet, the irresponsible and unjust character of our age leads to alienation from the world of common experience, to feeling 
isolated, unseen, ignored, exploited, and abused. The pervasive sense of alienation from the given normative world engenders resistance to the moralised understandings of justice in much contemporary political theory, which focuses on clarifying our responsibilities with rigour and precision but provides considerably less guidance on what we might actually do about injustice. The works reviewed here, in contrast, start from a place of determined resistance, as each author refuses the consolations of idealistic moralising in favour of a renewed commitment to politics, holding to the belief that the pursuit of justice requires the remaking of the rules and relationships that make up the given normative order, and that we must work towards a profound political transformation if we want to reduce the injustice in our world.

In shifting the starting point for thinking about global justice these works engender questions about how we should go about theorising justice, in particular how it can be linked back to the lived experience of injustice. These works orient justice theory towards the necessity of radical reform, and as a consequence the politics of defining and pursuing justice come to the fore in all three texts, as does the issue of how we take responsibility, both for our response to injustices, which we may be unavoidably complicit in, and for furthering the political transformations necessary to combating global injustice.

Collectively Brooke A. Ackerly, Michael Goodhart, and Catherine Lu provide a clear-eyed critique of the inadequacies of what Goodhart dubs "IMT" (Ideal Moral Theory, which he convincingly argues has dominated discussion of global justice for nearly 40 years), and while their criticisms are unlikely to dissuade the true believer, they provide an urgent call-totheoretical-arms, showing the benefit of thinking differently about justice. Additionally, across the three books, a varied intellectual tool-kit for doing what Ackerly calls "grounded normative political theory" is brought together and will hopefully inspire more empirically grounded contributions to a consolidating field of critical global justice scholarship. ${ }^{1}$ Finally, the authors' efforts should inoculate global justice scholarship against understandings of justice focusing on the volitional acts of individuals rather than the careful examination of the structural conditions, institutional histories, and unequal distributions of social power in which individuals act. Together these books demonstrate the vital need to think about responsibility and justice in terms of the wider social conditions that perpetuate injustice, narrow our emancipatory horizons, limit which agents are recognised as fully responsible, shape our sense of justice itself, and frustrate our efforts at political transformation.

As with all academic work that tries to think differently there are limitations and inconsistencies in these books, but they succeed in their most fundamental task, which is clearing a trailhead. My lingering concern is that of a fellow-traveller keen to follow their path: 
I worry about the intellectual provisions collected in preparation for the work ahead. Each writer is motivated by an egalitarian commitment to include everyone in the pursuit of justice, yet the deeply democratic quality of this ethos is under-developed. Goodhart is the most willing to speak of democracy directly, but both Lu and Ackerly clearly embrace democratic political institutions and practices. Yet across all three books there is insufficient appreciation of the burden that their prescriptions place not only on democratic institutions but also the democratic character of individuals and communities. I worry our democratic culture is strained and badly diminished by neglect and vandalism, such that rethinking justice and responsibility in these essential and timely ways must include more consideration of how much care and attention our democratic culture needs if we are to be equal to the task ahead.

\section{The importance of new beginnings}

Goodhart's book is the only one that begins with an extended critique of the literature on global justice, and his critique of IMT is sensitive and comprehensive. Yet, his most important accomplishment is surveying the gap between highly idealised notions of justice and actual political experience. If the gap opens too wide, then justice and politics come to seem hopeless, with theories of justice offering bromides and politics reduced to self-interest. All three authors recoil from the desire for a complete ideal of justice, beginning instead from within the horizon of our very unjust world. Beginning within the world of injustice remains intellectually unorthodox, such that academic convention does not dictate a preferred angle of approach. The freedom from convention allows each author to introduce their investigation in terms of the particular problems they take to be most pressing.

Ackerly (2018: 28) highlights how conventional global justice theorist start by reflecting on various global injustices occurring out in the world, far from the author or her presumed readers, and then arranging the world in a more just, if highly abstract, manner. ${ }^{2}$ In contrast, Ackerly locates the starting point for global justice in the everyday experience of those suffering injustice and their struggle against injustice. She sets out several reasons for this, the most important of which is understanding, and acting to correct, injustice is a difficult task always done under conditions of incomplete and imperfect information; as a consequence, to accurately know or combat injustice the experience of those suffering injustice should have a privileged position in relation to abstract theorising. Given injustice is encountered in the actual world of everyday experience, we require a theory of global justice connected to the everyday, something that IMT cannot do. 
By starting with the experience of injustice, Ackerly argues we are better able distinguish between specific unjust acts (committed by individual, group, or collective agents) and "injustice itself." While she acknowledges the importance of addressing specific harmful acts, and thinking carefully about accountability for culpable agents, Ackerly's real goal is to think about how we address injustice itself, which refers to the practices, institutions, political and economic structures, and cultural norms that enable unjust actions, while obscuring the true nature and extent of injustice in our world. Injustice itself is expressed through the exploitable and oppressive power hierarchies that structure everyday experience. While Ackerly (2018: 84 ) is clear that "power inequalities are part of human life, and therefore human life always contains seeds of injustice itself," she does not use this axiomatic proposition to give a comprehensive account of what justice should entail. Instead, she notes harmful actions are both unjust and potential evidence of injustice itself. The identification of injustice itself (the harmful arrangement of power inequalities) requires empirical inquiry that privileges the experience of those suffering from injustice to draw out when injustice itself is "constituted by the power dynamics of both the material practices and the meaning-making practices of human social life." (Ackerly 2018: 73) Injustice itself, then, is analysed in terms of the complex causality of unjust harms in our globalised world, the development and manipulation of power inequalities to exploit and oppress the vulnerable, and the normalisations that obscure the operation of injustice itself and facilitate our denial of responsibility for it. Ackerly argues that our analysis must be grounded, not only in the details of contemporary political life, but also in the efforts of those struggling against injustice itself to transform the social order in profound ways. In shifting the starting point for global justice, Ackerly (2018: 17) gives us a far more vital question to wrestle with: "What should we do in the face of injustice itself?" Her response centres on building solidarity with those who experience injustice through practices of connected activism that develop our collective capacities for action through collaborative efforts focused on egalitarian leadership structures.

Similarly, Goodhart is impatient with IMT's inability to grasp the real problems of global injustice, in particular the hierarchical and highly unequal distribution of power and wealth. While Goodhart shares Ackerly's concern to theorise injustice in solidarity with those suffering from injustice, he is initially more concerned with diagnosing the problems of IMT, in particular how it functions ideologically_an insight he briefly dramatizes by recounting the cognitive dissonance felt while teaching global justice theory in spaces in which global injustice is rife (2018: 2-4). Goodhart (2018: 28) argues IMT not only misunderstands global injustice, it also distorts our thinking by inviting us to conceive of injustice as the opposite of 
"spotless" justice, as a deviation from an ideal set of principles. This is why getting the principles right is so vital within IMT, as the ideal of justice must be correct to ensure our efforts at reform in the real world are legitimate. Goodhart wants to "defamiliarize" IMT (2018: 5), to render it strange and pathological, asking "how on earth could anyone imagine that that's a sensible or appropriate way to think about these problems?" He draws out the key failings of IMT by tracking its tendency toward analytical paralysis and the subordination of politics to morality. As a consequence, IMT functions ideologically to obscure the partisan values that motivate and shape its approach to global justice, and to exclude the experiences and claims of those suffering from actual injustice. IMT obstructs consideration of the deeper structural transformations to the political order that might make the world more just and treats politics as a threat to the pursuit of justice-global justice on the conventional model is best left to the experts and has an uneasy relationship with substantive political or economic democracy.

Usefully, Goodhart's extended consideration of IMT is not focused on disproving particular theories or showing the inconsistency of technical arguments, but rather challenges our attachment to the logic and rhetoric of IMT. Goodhart's strategy goes beyond defamiliarization, as in the second and third parts of the book he sets out his positive project to develop a theory of justice that contributes to the struggle against injustice, which he terms a "bifocal approach". Contrasting his account with the realist turn in political theory, Goodhart suggests a critical and realistic justice theory has to work toward two distinct goals. On one hand, it needs to be sceptical of any account of justice in order to make clear the substantive and contestable values that motivate it, as well as its relation to wider economic and political structures. Any account of justice, for Goodhart, will be partisan, as it entails a political commitment to certain values. Therefore, a significant portion of justice theory's role will be to analyse and evaluate the existing terms in which justice is set out. On the other hand, a critical and realistic justice theory requires putting forward the normative values that guide and ground our partisan attachments. Goodhart's account of global justice rests on the value of democracy, in particular the democratisation of economic relationships and structures - linked to the redistribution of political power (2018: 136-145). In contrast to IMT, Goodhart wants to shift the focus of political theory away from justifying our inevitably partisan values in a complete and distinctly rational way, and towards the sustained consideration of the politics of injustice - both the politics keeping structural injustice in place and enabling individual crimes, and those necessary to achieving the social transformation needed to overcome injustice. Befitting his central metaphor, Goodhart's goal is to give us a new visual apparatus to 
supplement our perception, such that we can better see the present condition of injustice and better sight the normative horizon where we hope to build a more just world.

Where Ackerly and Goodhart start by reflecting on their attempts to teach students about global justice and the need for new ways of thinking our present, Lu's starting point is less personal and immediate as she starts in politics and in history. Lu begins with the complexities of colonial history, tracing the fate of the Herero and Nama peoples of South West Africa, from the genocide committed against them by German colonial forces, to their continued subjugation under the rule of the Union of South Africa, facilitated by the League of Nations, and up to their recent unsuccessful effort to win reparations from Germany (Lu, 2018: 1-5). The backdrop to Lu's investigation is the paradox of our current global moment, in which mechanisms for the pursuit of justice within post-conflict states, between states, and at the global level proliferate, but with very little effect in relieving the profound inequalities that the international order preserves and exacerbates.

By focusing on the violence and oppression written into the international order by the long history of European colonialism, Lu sets out to rethink the terms in which justice and reconciliation are understood in world politics. In particular, she focuses on how we should think about justice given enduring structural and historic injustices resulting from colonialism, while also appreciating that international order tends toward the maintenance of hierarchy rather than managing anarchy ( $\mathrm{Lu} 2018: 120)$. For $\mathrm{Lu}$, if we hope to achieve justice or reconciliation in the wake of political catastrophes, then attending to the postcolonial condition and enduring injustices inherent to the international order requires a series of clarificatory distinctions. First, between justice and reconciliation, which Lu argues should be seen neither as complimentary nor opposed, but rather as reflecting different aspects of achieving a more just world. Justice, as conventionally understood, is about redressing past harms and ensuring existing social relationships are not systematically harmful to individuals or particular groups; reconciliation, by contrast, speaks to our ethical relationship to the existing order in which we find ourselves, and is evaluated in terms of our degree of alienation from the existing order. Lu analyses the difference between interactional and structural accounts of injustice, as well as the distinctive problems thrown up by historical injustice, in particular how it can contribute to enduring contemporary injustices in surprising ways and to the sense of alienation felt by individuals and communities marginalised within the current order. (Lu 2018: 193) Lu makes two important revisions to conventional global justice theory. First, the complex connections between harms committed by individuals or groups and the structures that enable unjust actions can only be understood properly through a historically informed empirical and normative 
analysis, meaning that abstraction and idealisation of IMT is not only epistemologically contestable but morally inadequate because of its blindness to historical and structural injustice. And second, the normative adequacy of global justice theory depends on forms of moral and political engagement that go beyond the presumption of reasonable consent or meeting the conditions necessary for ideally rational dialogue, as an adequate global theory of justice will be the product, not precondition, of non-alienating political relationships and dialogue.

Despite their distinctive starting points, all three books share a defiant yet hopeful tone, as each author sets out to remake the study of global justice to better meet the challenges of the world and, in doing so, refuses both complacency and impotency. The texts are best read as complementary, with Goodhart's analysis of IMT fitting well with Lu's diagnosis of the gap between aspirational normative practices in world politics and the enduring injustice of our hierarchical international order, and both of them providing historical and ideological background for Ackerly's efforts to establish more immediate and effective forms of engagement between global justice activists and critical global justice scholars. The synergy among the authors is a testament to the practical importance and intellectual fecundity of taking a critical approach to global justice, though it also raises questions about how one goes about doing global justice theory differently.

\section{The tools of grounded normative theorising}

While criticism of IMT and the wider global justice literature is easy to come by, it is significantly harder to articulate how such work could be done differently. While each author aspires to do this, it is Ackerly who most clearly articulates the challenge doing global justice differently presents. She usefully speaks of her work as "grounded normative" theory (a label that fits Lu and Goodhart as well) and brings together various criticisms of conventional justice theory's excessive abstraction from the real world. Yet, if we want to think about justice from within lived experience, then we must address how analysis, critique, and prescription fit together. While I consider Ackerly's proposed methodology for global justice below, the problem she wrestles with is not taken up as directly in the other texts, and examining the less self-conscious approach of $\mathrm{Lu}$ and Goodhart reveals resonances between the books and highlights the value of Ackerly's explicit consideration of a methodology for global justice theory. ${ }^{3}$ Taken together we can begin to build a toolkit for critical and grounded work on global justice, which entails a focus on (1) historically situated causal analysis that preserves complexity; (2) conceptual distinctions that capture the distinctiveness of structural and historical injustice; (3) demarcations of the different obligations of backward and forward 
looking justice; (4) the role of power in the norms and practices related to justice; and (5) the development of new ways of linking the theorist of justice to both victims of injustice and those actively pursuing justice.

Lu's book has the least explicit reflection on the method necessary to grounded normative theorising, yet, in focusing her efforts on the pursuit of justice and reconciliation in an international order still very much shaped by colonial practices and structures, she nonetheless provides us with an exemplar of decolonial global justice theory. She argues

that if the configuration of state sovereignty in international order and processes of postcolonial state formation are interacting in causally fundamental ways to reproduce oppressive structured and structural injustices...then the problems of global justice cannot be wholly divorced from the challenge of decolonization. (Lu 2018: 277)

Therefore, for $\mathrm{Lu}$, it is imperative we think carefully about how to respond to the historic and structural injustice of an international order that functions as "a predatory system, forged by competition as well as cooperation between the great powers and other elites that came to dominate international and transnational relations over the course of the past two centuries." (Lu 2018: 120) This work involves an awareness that understanding and addressing structural injustice requires an appreciation that it takes place against an unjust baseline and is, therefore, difficult to recognise. ( $\mathrm{Lu} 2018$ : 123) Historical and structural injustices marginalise and oppress individuals and groups, while also enabling specific individual and institutional wrongdoing, but they often operate without explicit articulation, meaning we have to abandon any presumption of moral coherence, either in the past or some harmonious reconciled futureto-come. (Lu 2018: 141). Further, understanding injustice as structural leads to a recognition that there are "a complex array of social positions that individuals and groups may occupy in the social structures that produce injustice," and further, in looking at the specific harms of colonial and imperial domination, a structural analysis "is not likely to support simplistic division of colonizers and colonized into perpetrator and victim roles." (Lu: 130)

$\mathrm{Lu}$ illustrates this by analysing the injustice suffered by Korean women forced into the "comfort" system of the Japanese military during the Second World War, where they were coerced into sexual labour and slavery. She draws out the complicity of the Korean authorities of the time, along with elites and opportunistic individuals seeking to benefit from the exploitation of vulnerable women. Further, many of the women were poor or working-class, often displaced from rural to urban areas by Japanese colonial policies, but also marginalised and vulnerable at the national level and within the domestic sphere. Lu demonstrates 
responsibility for injustice is not a zero-sum question and does not try to minimise the responsibility of individual Korean men and women who committed harms as well as Japanese military authorities, instead insisting we appreciate the true challenges presented by historical and structural injustices. This example shows the colonised were not always innocent and that contrasting structural injustices based on gender and class operate within colonial contexts. Further, understanding injustice in its complexity alters our evaluation of contemporary events as well, as recent conflicts between Japan and South Korea over the treatment of Korean women during the war has tended to absolve Korean institutions and individuals involved while obscuring the specific (and cross-cutting) injustices suffered by the women who were victimised. Lu provides an example of how to do grounded normative theory, even as she is more concerned with historical injustices than Ackerly or Goodhart. For Lu, attending to the ways the international society of states contributes to injustice though "its rules, customs, and practices" provides a way to identify responsibility for enabling the conditions that lead to intentional wrongdoing. ( $\mathrm{Lu} 2018$ : 141) With her focus on structural rather than interactional justice, Lu's work also highlights how a grounded normative theory is oriented towards future action, rather than the mere settling of accounts. The complexity revealed by attending to colonial injustice does not leave us with an imperative to right all past wrongs, but pushes us to think about how we might remake the social order so that it does not produce injustice. Lu focuses on how the international order could be transformed such that it can be affirmed by those currently marginalised and dominated.

Where Lu's took kit can only be observed indirectly, Goodhart provides more explicit reflections. At the centre of Goodhart's alternative is his bifocal approach, which suggests justice theory needs to attend to two sets of problems if we hope to successfully address injustice. Goodhart argues that, on one hand, we should see with an analytical lens, which enables us to understand the "conflicts over justice claims, over the meaning of justice and injustice themselves", appreciating "these conflicts originate in the divergent values and ideas animating rival ideologies." (2018: 117) On the other hand, he argues we should also see through a partisan lens that "refers to a particular modality of political contestation and political struggle - to the theory, strategy, and tactics of transformational politics" in the service of a democratic vision of global justice. (Goodhart 2018: 118) These lenses are brought together to give us a comprehensive vision of injustice, which includes a critical and realistic assessment of the material and ideological barriers to change.

The bifocal approach, then, provides a starting point for analysing and pursing global injustice. The analytical lens asks us to see that all moral principles or values motivating 
particular concepts of justice are contestable and prone to function ideologically, and they tend to obscure injustice by either hiding it from view or normalising our acceptance of significant harms. At the same time, Goodhart asks us to reconcile ourselves to remaining in the realm of ideology even when we articulate our own evaluations and prescriptions for addressing injustice, as our commitments are ideological in the sense that they reflect a situated and contingent evaluation of what should be done. Further, Goodhart (2018: 147-148) advocates a democratic and emancipatory conception of justice, which entails distinctive methodological commitments. Similar to Lu and Ackerly, Goodhart privileges the experience of those suffering from injustice, adopting a feminist standpoint epistemology for his "grounded, inclusive" approach focused on those suffering injustice as "real and potentially active participants in the co-production of knowledge and of theory" in order to avoid "the epistemic domination pervasive in global normative theory." (2018: 148) Further, his democratic commitments necessitate a dialectical approach that understands "injustice and emancipation as always provisional" and ensures the "incorporation of changing and contested understandings into our thinking about injustice to help ensure that our theories speak directly and meaningfully to the concerns of real people, to the everyday examples of domination, oppression, and exploitation that cause so much suffering in our world." (Goodhart 2018: 149) The standpoint and dialectical elements of his theory aim to disrupt "normal justice" by revealing how "past injustice lives on in our theories, our metaphors, our institutions and practices", and how "moral conceptions of justice like those proffered by many global normative theorists don't seem like solutions to the problems faced by many historically oppressed groups and in fact often seem to be the problem." (Goodhart 2018: 161) Goodhart explicitly sets out to reorient political theory, hoping to inspire a substantive change in how scholars in the field understand and carry out their work, but the book is weakest when it attempts the work of bringing realworld experience together with critical theoretical reflection in its final chapters because the lived experience of those suffering injustice is not fully integrated. It is on this point that Ackerly's explicit consideration of the methodology, and methods, of grounded normative theory has its greatest value.

Ackerly shares Lu and Goodhart's concern with theorising from the experience of injustice and as a result all three authors focus on "political power dynamics", refusing to limit their understanding of injustice to "economic relations and individual moral responsibilities." (2018: 64) It is when she considers how the interaction between the complex causality of political events and significant inequalities in political power result in injustice itself that Ackerly's methodological insights begin to reshape the problem of global injustice in ways that Lu and 
Goodhart do not quite manage. Through her sustained work with global justice activists, mostly in Bangladesh, Ackerly is more sensitive to the significance of how the specific harms that constitute global injustice in itself are normalised, and therefore rendered nearly invisible. (2018: 84) The critical approach to global justice taken by all three authors requires an understanding of injustice as rooted "in complex causality and power inequalities," which Ackerly argues requires us to work toward "redirecting social attention and to rethinking common social interpretations" of world politics, so that which is rendered invisible by being seen as normal, is revealed to be unjust and in need of urgent attention and action. (2018: 88) For Ackerly, the work of challenging the process of normalisation is about more than challenging how political theorists do their work, as she focuses on the "common ways in which social epistemologies are constructed and reinforced," identifying three processes that normalise injustice: "familiarity and habituation, misinterpretation of common patterns, and marginalization through fragmentation." (Ackerly: 88) By working closely with activists, Ackerly identifies the specific and personal ways both individuals suffering injustice, and those with unfulfilled responsibilities to correct injustice, need to reorient their understanding of their everyday experience.

Grounded normative theorizing, for Ackerly, is a methodology in which the theorist does not depend on her own reflections about how she would respond responsibly or on her imagination about how others would or should respond responsibly to injustice in order to understand the ethics of responsibility for injustice at play in our hearts and minds... grounded normative theorizing is a dynamic and multidimensional process of theorizing through engagement with struggle. (Ackerly 2018: 145)

All three authors set out to do this kind of theorising, to great effect, but the challenges remain. As Ackerly highlights, "How can those who live in relative privilege with respect to a struggle against injustice...join in the transformation of our societies from within in a way that supports and is allied with the approach of those oppressed, misunderstood, and marginalized by our societies?" (2018: 164) This difficult work will of necessity be experimental and requires ongoing critical self-reflection, and Ackerly's account makes the challenges explicit. Drawing on ideas found in the work of global justice activists, Ackerly provides the critical global justice scholar with five principles-in-practice, which provide intellectual and political markers for the journey ahead:

(1) utilizing intersectional analysis; (2) thinking about narrow issues with awareness of their cross-issue dimensions; (3) promoting the capacity for self- 
advocacy and other political skills of ourselves and of those throughout our web of partners and allies; (4) working against the complex forces that create obstacles to rights enjoyment by building community through connected activism; and (5) working in ways that enhance our learning. (Ackerly 2018: 192-193)

The value of Ackerly's specific methodological considerations, along with Lu and Goodhart's criticisms of conventional approaches in political theory, is that the call to make political theory less abstract or more realistic is given much greater specificity in these works. It is not only that the authors are empirically informed and politically aware, but their commitment to standpoint epistemologt means that the experiences of people struggling against injustice are given space and the authority of the theorist is properly chastened. Collectively, these authors have given us an important set of tools for addressing global injustice, and doing political theory more generally, in a way that attends to the real and pressing problems of our world.

\section{Politics of and for responsibility}

Iris Marion Young is a common reference point for all three authors, providing inspiration and, at times, a critical foil. One aspect of her thought in particular is given distinct expression in each book. Young distinguishes between advocates of deliberative democratic institutions and activists pursuing more radical democratic cultures, arguing the democratic activist "recommends that those who care about promoting greater justice should engage primarily in critical oppositional activity, rather than attempt to come to agreement with those who support or benefit from existing power structures.” (Young 2001: 671) Ackerly, Goodhart, and Lu all build on Young's insight that our responsibility for addressing structural injustice must be met through forward-looking political action. Lu calls for radical revisions to the international political order as such, arguing we need a political transformation that would allow "marginalized participants to engage as equals in a joint enterprise to construct a mutually affirmable and affirmed international and transnational social/political order." (Lu 2018: 276) Ackerly is less focused on the hierarchical structure of international politics as such, but insists that we have a responsibility to address injustice itself everywhere, along with an obligation to ensure that we take responsibility in a just way. She argues "we have to understand the project of addressing all forms of injustice itself as a political obligation that is not predicated on a moral obligation...taking responsibility for injustice itself means acting politically in ways that transform the politics." (Ackerly: 215-216) In both cases, our responsibility to pursue justice means we have to work towards political institutions and structures that are less exploitative 
and oppressive, and which do not systematically marginalise and harm whole categories of people. Goodhart, as mentioned earlier, is more willing to identify this political transformation as distinctly democratic. He sees the pursuit of global justice as requiring a "counterhegemonic politics" capable of the "marshalling and deployment of countervailing power against the dominant ideological formations that normalize and perpetuate injustice." (Goodhart 2018: 182) His call for an emancipatory, counterhegemonic politics finds its justification not only in assigning diffuse responsibility for structural injustice, which can only be met through efforts to transform political structures, but also in the affirmation of an ideological commitment to democracy. "Put differently, an emancipatory democratic politics must be constructed, and it must be democratic; it must insist on its core values, even while it reflexively understands them as contingent, provisional, and protean." (Goodhart 2018: 187) It is striking that each author connects taking responsibility for global injustice to the need for a transformation to a more democratic politics, but in each case the necessary conditions for such a politics are insufficiently considered.

The lack of attention to our current capacity for democratic political action is the fundamental worry generated by these inspiring and necessary books. Acting democratically requires institutions in which we can act collectively, and even our existing and highlyimperfect democratic institutions are in a rather sorry state today. But democracy requires more than better institutions and laws; as the authors draw out repeatedly, injustice has its deepest causes in our fundamental understandings of self, other, and community. The political pursuit of a more just world must be connected to the task of repairing and repurposing our existing democratic culture, not only reminding us of the existing resources we will need to mobilise, but also showing us that we have perhaps never been as democratic as we have hoped to be. While there are hints the authors recognise this need, there is insufficient appreciation of the way struggles against injustice have long histories and inspiring contemporary commitments to radical democratic habits, values, practices, and institutions. Making connections, across time and space, between explicitly democratic political movements would give a better sense of the resources available to draw on, the wealth of strategic knowledge on building and organising for transformative change, and wider grounds for solidarity than the at times narrower focus on the links between oppression/domination and racialised identity - a hugely pressing problem for thinking about justice today is how solidarity can be built across divides of difference that may be very uncomfortable, but this problems is being, and has been, addressed in democratic political activism. I have a sense that each author would agree with 
my claims here, and think their work at least attempts to draw on this rich democratic culture, but even so, I would suggest that it could usefully be more explicit.

Yet, as I stated at the outset, we live in irresponsible and unjust times, so I cannot end on a purely optimistic note. Our current moment precludes such resolution, we must live with and in the dissonance. For all of the talk of responsibility in these books, there is little discussion of what is necessary to the social construction of responsible democratic agents, whether individual or collective. ${ }^{4}$ Ackerly gets close with her account of how activism builds webs of connection that enable individuals to join together to take responsibility for injustice. Yet, even here, there is a presumption we are able and ready to take responsibility for injustice understood in radically new ways. This raises two important worries. First, do individuals and groups have the psychological and emotional preparation required to take responsibility for consequences they have contributed to indirectly, and to then act for the sake of others who they may only be connected to very indirectly? And, second, even where individuals and groups are willing and able to take responsibility for injustice, the social and political processes and institutions through which they would need to act either do not exist, are co-opted by other better-organised and less democratic actors, or are badly neglected and dysfunctional. Again, my sense is the authors would agree with me, but if so, it is important to wonder why more attention is not given to how we might prepare ourselves to take responsibility for injustice. Perhaps it is because, at a time when there are many difficult political questions, we are afraid this is a question we do not know how to answer.

\footnotetext{
${ }^{1}$ See, for example, Bell (2019), Dunford (2017), Flikschuh (2014), Hutchings (2019), McKeown (2016), and Young (2011)

${ }^{2}$ For a similar and more extended analysis of how conventional global justice theory frames the geography of injustice see Hoover (2018: 104-114).

${ }^{3}$ There has been increased interest in the methods adopted in political theory (Blau 2017; Herzog and Zacka 2019; Leopold and Stears 2008; Scavenius 2017), and an ongoing discussion about methods in normative political theory (Miller 2002; Mills 2005; Sangiovanni 2007; Simmons 2010; Stemplowska 2008). There has, however, been less work on the methods involved in normative political theory that aspires to start from lived experiences of injustice, with notable exceptions in feminist and pragmatist political theory (Dieleman, Rondel, and Voparil 2017; Jaggar 2014).

${ }^{4}$ See Hoover (2017) for more on this point.
} 


\section{Bibliography}

Ackerly BA (2018) Just Responsibility: A Human Rights Theory of Global Justice. New York: Oxford University Press.

Bell, D (ed) (2019) Empire, Race and Global Justice. Cambridge: Cambridge University Press.

Dieleman S, Rondel D and Voparil C (eds) (2017) Pragmatism and Justice. New York: Oxford University Press.

Dunford, R (2017) Toward a decolonial global ethics. Journal of Global Ethics 13(3): 380397.

Flikschuh K (2014) The Idea of Philosophical Fieldwork: Global Justice, Moral Ignorance, and Intellectual Attitudes. Journal of Political Philosophy 22(1): 1-26.

Goodhart M (2018) Injustice: Political Theory for the Real World. New York: Oxford University Press.

Herzog L and Zacka B (2019) Fieldwork in Political Theory: Five Arguments for an Ethnographic Sensibility. British Journal of Political Science 49 (2): 763-784.

Hoover J (2017) Democratic Moral Agency: altering unjust conditions in practices of responsibility. Moral Agency and the Politics of Responsibility, Debiel T, et al. (eds). London: Routledge: 21-35.

Hoover J (2018) Developing a Situationist Global Justice Theory: From an Architectonic to a Consummatory Approach. Global Society 33(1): 100-120.

Hutchings K (2019) Decolonizing Global Ethics: Thinking with the Pluriverse. Ethics \& International Affairs 33(2): 115-125.

Jaggar A (ed) (2014) Gender and Global Justice. Cambridge: Polity.

Lu C (2018) Justice and Reconciliation in World Politics. Cambridge: Cambridge University Press.

McKeown M (2016) Global Structural Exploitation: Towards an Intersectional Definition. Global Justice: Theory, Practice, Rhetoric 9(2): 155-177.

Miller D (2002) Two Ways to Think About Justice. Politics, Philosophy \& Economics 1(1): $5-28$.

Mills, CW (2005) "Ideal Theory" as Ideology. Hypatia 20(3): 165-184.

Sangiovanni, A. (2008) Justice and the Priority of Politics to Morality. The Journal of Political Philosophy 16(2): 137-164.

Scavenius, T., 2017a. Fact-sensitive political theory. Critical Review of International Social and Political Philosophy 22(1): 5-17. 
Simmons AJ (2010) Ideal and Nonideal Theory. Philosophy \& Public Affairs 38(1): 5-36.

Stemplowska Z (2008) What's Ideal About Ideal Theory? Social Theory and Practice 34(3): 319-340.

Young IM (2001) Activist Challenges to Deliberative Democracy. Political Theory 29(5): 670-690.

Young IM (2011) Responsibility for Justice. Oxford: Oxford University Press. 